\title{
Erratum to: Nocardia bhagyanesis sp. nov., a novel actinomycete isolated from the rhizosphere of Callistemon citrinus (Curtis), India
}

\author{
Radha Vaddavalli • Sneha Peddi • \\ Srilekha Yadav Kothagauni • \\ Venkateswar Rao Linga
}

Published online: 22 May 2014

(C) Springer International Publishing Switzerland 2014

\section{Erratum to: Antonie van Leeuwenhoek (2014) 105:443-450 DOI 10.1007/s10482-013-0093-0}

Subsequent to the publication of the above paper it has been brought to our attention that the species epithet proposed for the taxon represented by strain VRC $07^{\mathrm{T}}$ is not grammatically correct as "Nocardia bhagyanesis" should have been proposed as Nocardia bhagyanarayanae. We propose here the corrected name for the taxon represented by strain $\mathrm{VRC} 07^{\mathrm{T}}$.

Description of Nocardia bhagyanarayanae sp. nov.

Nocardia bhagyanarayanae sp. nov. (bha.gy.a.na.ra.ya'nae: N.L. fem. gen. n. bhagyanarayanae, of
Bhagyanarayana, named in the honour of Prof. Bhagyanarayana Gaddam, a renowned Indian mycologist).

The description of the species is as given for "Nocardia bhagyanesis" in Vaddavalli et al. (2014) Antonie van Leeuwenhoek 105:443-450.

The type strain is strain $\operatorname{VRC}^{\mathrm{T}}\left(=\mathrm{KCTC} 29209^{\mathrm{T}}\right.$ $=\operatorname{MTCC} 11725^{\mathrm{T}}=$ ATCC BAA-2548 ${ }^{\mathrm{T}}$ ).
The online version of the original article can be found under doi:10.1007/s10482-013-0093-0.

\section{R. Vaddavalli}

Department of Botany, Osmania University, Hyderabad 500007, Andhra Pradesh, India

\section{S. Peddi}

Department of Pharmacy, Aditya Pharmaceutical College,

Kakinada 533 437, India

\section{S. Y. Kothagauni · V. R. Linga ( $\square)$}

Department of Microbiology, Osmania University,

Hyderabad 500007, Andhra Pradesh, India

e-mail: vrlinga@gmail.com 